\title{
Laboreal
}

Volume $17 \mathrm{~N}^{\circ} 1$ | 2021

Trabalhar hoje: mudanças, permanências, estratégias, reinvenções

\section{Subjetividade e trabalho: entre mal-estar e bem- estar - Jorge Juan Román Hernández, Dominique Lhuilier, José Newton García de Araújo e Andrea Pujol}

Subjetividad y trabajo: entre el mal-estar y el bien-estar - Jorge Juan Román Hernández, Dominique Lhuilier, José Newton García de Araújo y Andrea Pujol Subjectivité et travail: entre mal-être et bien-être - Jorge Juan Román Hernández, Dominique Lhuilier, José Newton García de Araújo et Andrea Pujol Subjectivity and work: between ill-being and well-being - Jorge Juan Román Hernández, Dominique Lhuilier, José Newton García de Araújo and Andrea Pujol

\section{Gilles Amado}

Tradutor. José Newton García de Araújo (jinga@uol.com.br)

\section{OpenEdition}

\section{Journals}

\section{Edição electrónica}

URL: https://journals.openedition.org/laboreal/17500

DOI: $10.4000 /$ laboreal. 17500

ISSN: 1646-5237

\section{Editora}

Universidade do Porto

\section{Refêrencia eletrónica}

Gilles Amado, «Subjetividade e trabalho: entre mal-estar e bem-estar - Jorge Juan Román Hernández, Dominique Lhuilier, José Newton García de Araújo e Andrea Pujol», Laboreal [Online], Volume 17 №1 | 2021, posto online no dia 18 junho 2021, consultado o 20 junho 2021. URL: http:// journals.openedition.org/laboreal/17500 ; DOI: https://doi.org/10.4000/laboreal.17500

Este documento foi criado de forma automática no dia 20 junho 2021.

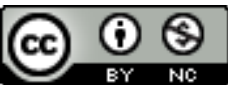

Laboreal está licenciado com uma Licença Creative Commons - Atribuição-NãoComercial 4.0 Internacional. 


\section{Subjetividade e trabalho: entre mal- estar e bem-estar - Jorge Juan Román Hernández, Dominique Lhuilier, José Newton García de Araújo e Andrea Pujol}

Subjetividad y trabajo: entre el mal-estar y el bien-estar - Jorge Juan Román Hernández, Dominique Lhuilier, José Newton García de Araújo y Andrea Pujol Subjectivité et travail: entre mal-être et bien-être - Jorge Juan Román Hernández, Dominique Lhuilier, José Newton García de Araújo et Andrea Pujol Subjectivity and work: between ill-being and well-being - Jorge Juan Román Hernández, Dominique Lhuilier, José Newton García de Araújo and Andrea Pujol Gilles Amado

Tradução : José Newton García de Araújo (jinga@uol.com.br)

\section{NOTA DO EDITOR}

Manuscrito recebido em: $16 / 11 / 2020$

Aceite após peritagem em: 09/04/2021

\section{Subjetividade e trabalho em três línguas}

Esta obra é particularmente interessante, em razão de sua originalidade. Ela desenvolve, de fato, em três línguas (francês, espanhol e português), várias das comunicações apresentadas por pesquisadores cubanos, latino-americanos e francófonos (França, Quebec e Suíça), por ocasião do Simpósio Internacional que 
ocorreu em outubro de 2018, em Havana (Cuba), sobre o tema "Subjetividade e trabalho". Essa manifestação agrupou cerca de 450 participantes, representantes de uma diversidade de abordagens disciplinares (ergonomia, psicologia do trabalho, medicina do trabalho, sociologia, economia, direito, filosofia e psicanálise). Seu objetivo de humanização do trabalho, particularmente através da exploração de questões de saúde permitiu, ao mesmo tempo, a elaboração de produções científicas e a apresentação de ações de prevenção, desenvolvidas em diferentes ambientes de trabalho.

2 Cinco temas intitulando os capítulos foram escolhidos para relatar esses trabalhos: transformação do trabalho e subjetividade; tempo, atividade e subjetividade; gênero, saúde e trabalho; trabalho precário, trabalho informal, trabalho invisível; intervenção e pesquisa-ação.

\section{Um breve resumo de cada contribuição}

3 O primeiro texto desta obra (de autoria do psicólogo cubano, anfitrião e coorganizador do Simpósio, Jorge Juan Román Hernández) denuncia o ardil representado pela exigência de comprometimento, por parte dos trabalhadores, atitude valorizada pelos empregadores, noção cara aos especialistas do comportamento organizacional e aos teóricos norte-americanos do management. $\mathrm{O}$ autor demonstra que o comprometimento até pode promover efeitos positivos sobre a saúde no trabalho, mas pode também levar a um intenso desgaste e a sofrimentos físicos e psicológicos. Enquanto estratégia gerencial, ele pode ser fonte de um processo de alienação.

4 Danièle Linhart, cujos escritos em sociologia do trabalho têm lugar de destaque na França, vai no mesmo sentido, estigmatizando esse management "vertiginoso", que, fazendo apelo à autonomia dos empregados, na verdade a engessa com toda sorte de dispositivos e de ferramentas impostas, no âmbito de uma relação de subordinação que, na realidade, favorece a individualização e a competição, fonte de tensões sociais e intrapsíquicas.

O presenteísmo - presença no trabalho apesar de problemas de saúde não expressos constitui um dos fenômenos estudados pela psiquiatra Edith Seligmann-Silva, com base em numerosas pesquisas internacionais. Ela explora suas raízes sociais e suas manifestações, no seio de organizações diversas, além de sua expansão, principalmente no Brasil, antes de especificar seus desafios éticos.

6 João Batista Ferreira, psicólogo, explora em seguida vários dispositivos dr captura da vitalidade para fins produtivos típicos do mundo neoliberal, bem como as formas de resistência que se opõem a esse modo de exploração. Este estudo é baseado em cinco pesquisas que usam o método de cartografia das formas de vida, realizadas junto a trabalhadores terceirizados, eletricistas, professores e psicólogos.

7 Marc-Eric Bobillier-Chaumon, psicólogo do trabalho e especialista no impacto das tecnologias no mundo do trabalho, demonstra de que forma as novas gerações de tecnologias se desenvolvem, atualmente, produzindo, ao mesmo tempo, coerções e recursos inéditos, visando impulsionar a evolução de profissões e competências. 0 engajamento subjetivo dos profissionais, nesses ambientes, comporta riscos, uma vez que as ferramentas desenvolvidas seguem essencialmente uma lógica tecno-centrada, 
em detrimento de uma abordagem mais antropo-centrada, com base nas capacidades e na inteligência prática.

O texto apresentado por Selma Lancman e Seiji Uchida refere-se às políticas públicas de saúde no trabalho, no Brasil. Sua ação, conduzida de acordo com a psicodinâmica do trabalho, junto a responsáveis por centros de saúde no trabalho, em São Paulo, possibilitou evidenciar diversos aspectos que intervêm na construção da intersetorialidade, bem como nos serviços de assistência aos trabalhadores.

Dois estudos, feitos a partir de bancos de dados e de análises estatísticas, no setor de construção, pelo Instituto Nacional da Saúde dos Trabalhadores (Cuba) versaram sobre os recursos psicológicos dos trabalhadores (considerados fator-chave da saúde) com relação à capacidade de trabalho. De acordo com as conclusões de Georgina López Pulmar, Felix Amador Romero e Roselia Bustamante Rojas, seria pertinente atribuir uma importância tangível a esses recursos psicológicos individuais, caso se queira desenvolver estratégias de intervenção e de formação, na perspectiva da saúde no trabalho.

10 A psicóloga argentina Andréa Pujol apresenta, em seguida, suas reflexões, a partir de uma pesquisa-ação com foco no sofrimento vivido pelos professores universitários, face a transformações institucionais, particularmente à gestionarização crescente da estratégia acadêmica. Ela gera uma sobrecarga de tarefas administrativas e conflitos éticos, decorrentes do recuo da implicação, assim como da restrição da autonomia. Donde a necessidade de se criarem espaços de deliberação que sejam capazes de ajudar a repensar o trabalho, de modo a aliviar o mal-estar.

11 Foi dentro de uma universidade pública colombiana que Daniel Ernesto Gómez Giraldo, Lina Marcela Gil Congote e Johnny Orejuela Gómez estudaram, graças a uma abordagem fenomenológica, a experiência de dez pesquisadores, em relação ao reconhecimento de seu trabalho. Eles mostram que é a atividade de ensino, a socialização dentro da comunidade científica e o impacto de seus trabalhos junto a ela que constituem elementos-chave de tal reconhecimento, e que isso pode ser posto em perigo, essencialmente em função de questões institucionais.

12 Duas ergonomistas, pesquisadoras da área do tempo no trabalho, Corinne Gaudart $\mathbf{e}$ Sophie Prunier-Poulmaire, defendem, em seguida, a partir de histórias de situações concretas, junto do trabalho e de sua organização, assim como de uma abordagem holística do tempo de trabalho, a ideia de que o tempo quantitativo (horas e durações) não pode ser separado do tempo qualitativo (o que se faz com ele), para não se negligenciarem inúmeros efeitos deletérios sobre a saúde no trabalho. Trata-se, portanto, de uma articulação bem pensada desses dois aspectos que permitiriam que os trabalhadores se apropriassem do tempo, preservando sua saúde.

13 O estudo dos efeitos dos dispositivos de inserção pelo trabalho, para sujeitos egressos do sistema penitenciário ou de hospitais psiquiátricos, na Argentina, permitiu a Silvana Melissa Herranz apontar certos elementos paradoxais das exigências institucionais: uma vez que o mundo profissional privilegia a posição do sujeito "autônomo" e "empreendedor", como ter acesso a tal autogestão nas instituições de "reabilitação" que prescrevem, acima de tudo, a dependência e a submissão? Discussões oriundas de uma análise crítica dos trabalhos de pesquisa sobre este assunto são oferecidas aqui.

14 As pesquisas sobre o laço gênero/trabalho estão sendo desenvolvidas mundo afora. Entre elas, a de Maria de Lourdes Marrero Santos e suas colegas cubanas é 
particularmente original. Com efeito, ela estuda o impacto de determinados fatores de risco no trabalho sobre a concepção de bebês, junto a uma coorte de 521 trabalhadoras grávidas pertencentes a diversas profissões. Além dos riscos clássicos ligados ao ambiente físico e desergonômico, essa pesquisa revela o estresse no trabalho como sendo um risco "perinatal" que se deve levar em conta, quando do recrutamento de trabalhadores.

No Chile, Elisa Ansoleaga e Alba Barrera demonstraram a prevalência das violências psicológicas e sexuais feitas às mulheres, em diversos setores da economia, em três grandes regiões metropolitanas (Santiago, Concepción, Valparaíso). Sua metodologia baseou-se num estudo transversal quantitativo, representativo da população assalariada.

Para concluir, neste campo do gênero, Claudine Schalck, obstetra e pesquisadora em psicologia do trabalho, explorou as violências obstétricas, ou seja, os maus-tratos suportados pelas mulheres, por ocasião do nascimento de seus filhos. Deletérias para as mulheres, essas violências também o são para os cuidadores, muitas vezes levados a fazer um "trabalho sujo". Donde a necessidade de construir uma parceria autêntica entre as parturientes e os cuidadores, de modo que o reconhecimento e a autoestima possam ser valorizados.

17 Um dos aspectos do trabalho também é o fato de que ele pode ser precário, informal ou invisível. Trata-se do objeto do quarto capítulo dessa obra. Uma equipe de pesquisadores brasileiros - Jorge Tarcísio da Rocha Falcão, Cleverson Pereira de Almeida, Maria Regina Greggio e José Newton Garcia de Araújo - discute três casos de atividades precárias em diferentes contextos, o de vigia noturno, o de um necrotomista e o de uma professora "polivalente". A partir da abordagem da clínica da atividade e da noção de "trabalho sujo", os autores afirmam que a precariedade estaria ligada à diminuição do trabalho coletivo, intimamente ligada às manifestações de sofrimento no trabalho.

18 O último capítulo é dedicado à transformação do trabalho por intermédio de intervenções e de pesquisas-ação. Ele é aberto com a contribuição de Ludmila de Vasconcelos, Fernanda Tarabal, Admardo Gomes Junior e Jacques Rhéaume que apresenta diversas abordagens teórico-clínicas do trabalho, capazes de esclarecer as questões de saúde e as modalidades de intervenção que permitem facilitar seus aspectos vitais, e podem esclarecer seus desafios. Assim, essa equipe pluricultural e pluridisciplinar detalha os possíveis laços entre ergologia e psicanálise, a psicodinâmica do trabalho, a pesquisa-ação e a abordagem socioclínica, a psicossociologia e as histórias de vida.

Enio Rodrigues da Silva, Maristela Pereira e Vanessa Andrade de Barros, psicólogos brasileiros, esclarecem em seguida o conceito de gesto profissional, visto como categoria analítica centrada na atividade. Dois exemplos de intervenção, no setor hospitalar, são detalhados sob esse ponto de vista, com base em referências à ergologia e à psicossociologia do trabalho.

O texto proposto por Fernanda Spanier Amador e Maria Elizabeth Barros de Barros discute os movimentos (continuidade/descontinuidade) que se produzem entre "normatividade vital" e "normatividade social", em referência aos trabalhos de G. Canghilhem e Y. Schwartz. Essas reflexões são baseadas em dados recolhidos durante 
intervenções realizadas no campo das políticas públicas brasileiras, principalmente na esfera da educação social.

Sob a perspectiva da clínica da atividade, Luciana Gomes Albuquerque e Claudia Osório da Silva apresentam, em seguida, uma intervenção clínica num centro brasileiro de atendimento psicossocial, evidenciando os bons resultados do diálogo sobre o trabalho para aumentar sua qualidade.

Em face do sofrimento no trabalho de professores do Quebec devido a uma organização do trabalho problemática, Simon Viviers, Marie-France Maranda, Nathalie Morel e Isabelle Ruelland elaboraram, junto com uma federação sindical de professores, um dispositivo de intervenção destinado a restaurar seu poder de agir e a oferecer, dessa forma, um destino "político" ao sofrimento.

23 Na França, Malika Litim e Julie Cochin realizaram uma pesquisa-ação em uma coletividade territorial, a respeito da problemática da recolocação dos funcionários. Seu dispositivo original, que leva em conta ao mesmo tempo aspectos preventivos e curativos, levou à implantação de uma série de ações e a uma evolução do sistema de governança.

Para concluir, Dominique Lhuilier, coorganizadora do colóquio de Havana, conclui essa obra por uma proposta original, no campo da psicologia do trabalho: o trabalho de saúde. Trata-se aqui, sobretudo, de estratégias desenvolvidas por trabalhadores cuja saúde se fragilizou, pelo fato de desenvolverem compromissos entre as exigências do ambiente e a preservação da saúde. A autora demonstra, assim, que as escolhas e as estratégias têm duplo objetivo, de adaptação e de desenvolvimento.

\section{Concluindo a leitura do livro}

Apesar da diversidade das referências teóricas, metodológicas e culturais, ficamos surpresos com a proximidade das constatações e das reflexões acerca da saúde no trabalho.

A deterioração das condições de trabalho e sua gerencialização parecem atravessar as fronteiras e assim oferecer, infelizmente (?), terrenos de escolha para que inúmeros pesquisadores e profissionais da intervenção psicossociológica observem e analisem tais fenômenos, mas também e acima de tudo, tentem promover ações que reabilitem certa humanidade, no mundo do trabalho.

Não há duvida de que pesquisadores e profissionais de todos os horizontes encontrarão, nesta obra, uma matéria preciosa. 


\section{AUTORES}

\section{GILLES AMADO}

École des hautes études commerciales (HEC) ; Centre de Recherche sur le Travail et Développement (CRTD) ; Conservatoire National des Arts et Métiers (CNAM), 41, Rue Gay Lussac 75005 Paris, France. amado@hec.fr 